CORRECTION

\title{
Correction to: Between conflict and consensus: The Dutch depoliticized paradigm shift of the 1980s
}

\section{Merijn Oudenampsen ${ }^{1}$}

Published online: 25 August 2020

(c) Springer Nature Limited 2020

\section{Correction to: Comparative European Politics https://doi.org/10.1057/s41295-020-00208-3}

The author would like to correct the word correction from "Public" to "Social" in Fig. 1 Caption. The correct Fig. 1 is given below.

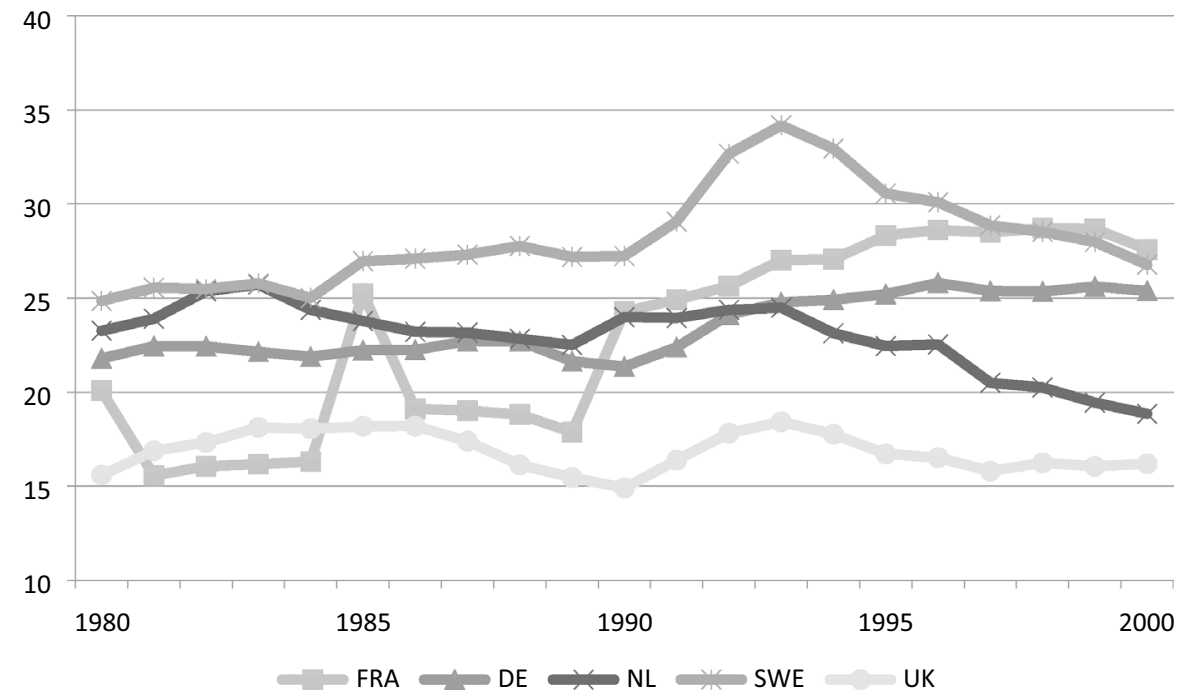

Fig. 1 Social spending in selected OECD countries as percentage of GDP. Source: OECD

The original article can be found online at https://doi.org/10.1057/s41295-020-00208-3.

Merijn Oudenampsen

m.oudenampsen@uva.nl

1 Faculty of social sciences, University of Amsterdam, Room B4.16, Postbus 15629,

1001 NC Amsterdam, The Netherlands 
Publisher's Note Springer Nature remains neutral with regard to jurisdictional claims in published maps and institutional affiliations. 